\title{
O DISTANCIAMENTO QUE EXISTE ENTRE AS PESQUISAS DESENVOLVIDAS NAS UNIVERSIDADES E A INOVAÇÃO QUE CHEGA AS INDÚSTRIAS BRASILEIRAS
}

\author{
Márcio de Freitas Santa Ana ${ }^{1}$
}

RESUMO: O presente artigo teve como objetivo mostrar uma visão a respeito da inovação tecnológica, o papel das universidades nesse contexto e a relação destas com empresas para transferência de tecnologia. Foram utilizados como referências citações de artigos científicos e revistas de expressão nacional, que tratam dos temas apresentados . Foi mostrado que o Brasil possui características próprias que dificultam o investimento em pesquisas pelas universidades, a maior parte, de produção de inovações tecnológicas. O modelo teórico da Hélice Tripla será mostrado e analisará os relacionamentos entre as universidades, empresas e estado, o papel das incubadoras para aproximação entre universidades e empresas, a fim de facilitar a transferência de tecnologia da academia para o mercado. Será mostrada à importância do conhecimento incorporado pelas universidades brasileiras, entendendo as relações das pesquisas e suas perspectivas, além de mapas dos nossos cientistas no mundo e das distribuições das incubadoras no Brasil por regiões e uma tabela que define também as quantidades por estados.

Palavras - Chaves: Hélice Tríplice. Incubadora. Inovação.

\section{INTRODUÇÃO}

As inovações Tecnológicas aliadas ao empreendedorismo tem sido fator de grande importância para manutenção e criação de alternativas para as economias em todos os países. Investimentos em pesquisa e desenvolvimento, criação de novos serviços e produtos tem reinventado e até mesmo criado novas perspectivas de modelos de negócios. No Brasil a relações das universidades com as pesquisas tecnológicas e suas contribuições ainda buscam seus melhores dias, inclusive uma melhor eficiência na gestão pública para aproximar as empresas das universidades, a fim de, reduzir às distâncias e as desconfianças dos empresários brasileiros.

\footnotetext{
I Fundação Centro Universitário da Zona Oeste - UEZOI E-mail: ciedistancia@gmail.com.
} 
A incorporação do conhecimento, a inovação e a necessidade de competição global são conceitos muito recentes na empresa brasileira. O elo final da incorporação de valor ao produto consiste em uma inovação na linha de produção. Quase independente da natureza do produto essa etapa é essencial na introdução de um produto bem-sucedido ou na alteração de um produto tradicional. O lugar da inovação é, portanto na empresa CHAIMOVICH, 1999

O Brasil não se sai bem em rankings que apontam quais são as nações que mais inovam em produtos, serviços ou processos. O fruto que os países que mais inovam colhem, contudo, é bem conhecido: desenvolvimento econômico. A receita também: aproximação entre centros de pesquisa tecnológica, empresas e governo Revista Veja

No Brasil a Hélice Tríplice tornou-se um "movimento" para geração de incubadoras no contexto universitário (ALMEIDA, 2005). Com seu arranjo geométrico, o mesmo nos fornece um incentivo para procurar desequilíbrios entre a as dimensões institucionais nos arranjos $\mathrm{e}$ as funções sociais desempenhadas por estes arranjos. Os atritos entre as duas camadas (baseadas no conhecimento das expectativas e interesses institucionais), e entre os três domínios (economia, ciência e política) fornecem uma riqueza de oportunidades para resolver quebra-cabeças e inovação LEYDESDORFF, 2012.

\section{I.I Pergunta Problema}

Quais os efeitos do distanciamento entre às pesquisas desenvolvidas nas universidades e as inovações que chegam as empresas brasileiras para a competitividade no desenvolvimento econômico e social.

\section{I.2 Objetivo}

Analisar o problema do distanciamento entre às pesquisas nas universidades no Brasil e as inovações no mercado brasileiro 


\subsection{Objetivo Geral}

Mostrar a importância do conhecimento incorporado pelas universidades brasileiras, suas contribuições à pesquisa para o desenvolvimento, inovação e criação de novos produtos.

\subsubsection{Objetivo Específico}

Entender no Brasil as relações das universidades com as pesquisas e suas novas perspectivas.

\section{JUSTIFICATIVA}

A importância da Inovação de uma maneira geral está ligada direta ou indiretamente à sobrevivência das empresas, num mundo cada vez mais globalizado. A participação tímida das universidades brasileiras no processo de inovação tecnológica leva nossos cientistas a desenvolver pesquisas fora do país. A necessidade de mais parcerias externas na formação de mestres e doutores, a fim de agregar conhecimento científico, e mais incubadoras para estimular à aproximação empresas universidades

\section{FUNDAMENTAÇÃO TEÓRICA}

\section{I O Papel da Formação de Pesquisadores no Sistema de Inovação}

Estudos sobre inovação têm indicado, sistematicamente, a importância do sistema de ensino superior para a inovação tecnológica. Primeiramente, as instituições de ensino superior produzem resultados de pesquisa que podem ser diretamente apropriados pelas empresas no seu processo de inovação - seja para solução de problemas, seja para a criação de novos processos e produto. CIÈNCIA E CULTIRA. 
Revista Ibero- Americana de Humanidades, Ciências e Educação- REASE open $\mathbf{O}$ Access

\section{CIENTISTAS BRASILEIROS NO MUNDO}

Paises que mais receberan pesequladores brasileiros em 2015

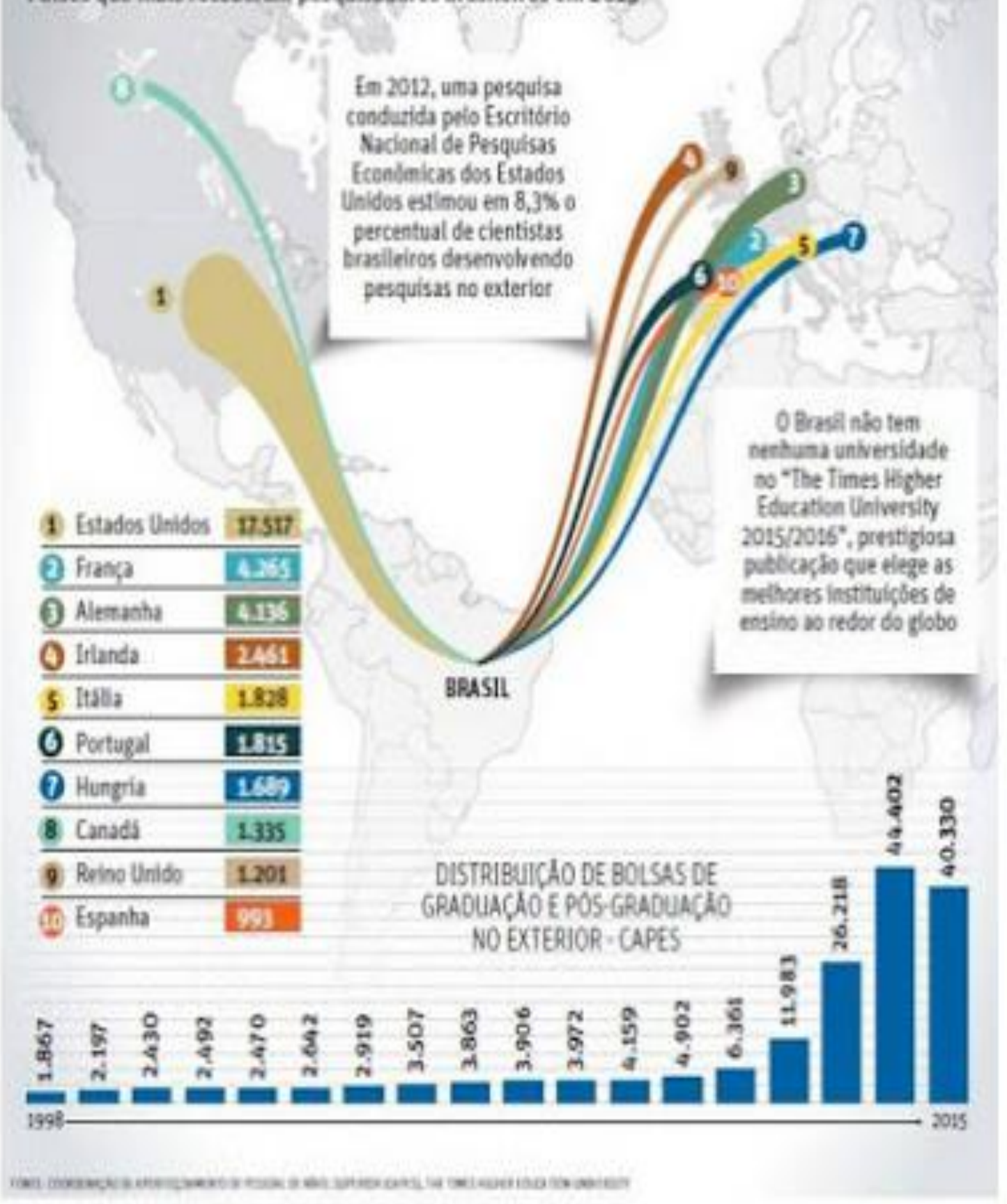

Figura 01 


\subsection{O Modelo Hélice Tríplice}

O modelo Hélice Tríplice caracteriza as relações entre o Governo, a Universidade e a Empresa e descreve e apresenta como pode ser criado um ambiente propício para a inovação, tornando a geração e a difusão do conhecimento inerente para o desenvolvimento da Sociedade CLOSS; FERREIRA, zoro

Uma das mais importantes teorias ligadas ao tema da inovação é a Hélice Tríplice baseada na interação entre universidade-empresa-governo como estratégia para a evolução das inovações na sociedade do conhecimento (ETZKOWITZ, 2000). Segundo o autor, o processo de inovação com base científica e tecnológica advém das universidades mediante a pesquisa acadêmica e a formação de capital humano altamente qualificado, que viabiliza a aplicação mercadológica dos resultados da pesquisa. É batizado de ímpeto empreendedor na academia ou de ciência empreendedora .MARZANO

\subsection{O Modelo Hélice Tríplice na visão das Universidades}

A participação da universidade implica maior aproximação com a sociedade e com sua problemática social e econômica, a qual, em contrapartida, ajudará a definir as prioridades e projetos da própria academia. Uma grande vantagem competitiva encontra-se em seu próprio corpo discente, pois o fluxo contínuo de indivíduos garante não só qualificação, mas igualmente a concepção de idéias inovadoras, ao contrário de laboratórios estabelecidos, de empresas ou governo onde tendem a repetir-se pessoas e rotinas. MARZANO zorr

\subsection{A Gestão de novos Modelos nas Universidades Brasileiras}

Modelos colaborativos, que promovam o empreendedorismo inovador, devem fazer parte da agenda das universidades, das empresas e do governo, sublinhou 
José Arana Varela, diretor-presidente do Conselho Técnico-Administrativo da FAPESP. REVISTA EXAME

\subsection{O Modelo Hélice Tríplice na visão da Indústria}

No caso da indústria, o modelo preconiza mudança conceitual profunda: de mero negócio competitivo,com fronteiras estanques, passa-se à colaboração com outras empresas e instituições tais como universidades, centros de pesquisa e agências de governo. A cadeia de valor vertical, do fornecedor ao cliente,é assim reconfigurada e o modelo tradicional, centrado em desenvolvimento, produção, marketing, e venda de produtos tangíveis, cede lugar à interação permanente dentro da tríplice Hélice, com pesquisas conduzidas conjuntamente,parcerias público privadas, investimentos em laboratórios e cursos universitários, formação de empresas dentro da universidade e assim por diante. MARZANO 201

\subsection{O desafio na Criação de Idéias na Indústria brasileira}

Um grande desafio é a criação de idéias patenteáveis nas empresas, quesito no qual a indústria no Brasil e em São Paulo também mostra pouca competitividade. Em São Paulo, mesmo com o grande dispêndio em P\&D feito por empresas, para cada mil pesquisadores empregados por empresas geram-se apenas cinco patentes registradas no país (Inpi), proporção que cai para I,9 quando se contam as patentes no United States Patent and Trademark Office (USPTO). REVISTA EXAME

\subsection{Incubadoras no Brasil}

No Brasil, o movimento de formação de incubadoras é mais recente quando comparado aos Estados Unidos e surge na década de 1980, com a iniciativa da CNPq em criar as primeiras instituições a apoiarem os empreendimentos inovadores do país, estas instituições contemplaram as cidades de Campina Grande (PB), Manaus 
(AM), São Carlos (SP), Porto Alegre (RS) e Florianópolis (SC). Diante desta decisão, foi criado em 1984 o ParqTec - Fundação Parque de Alta Tecnologia de São Carlos onde foi instalada a primeira incubadora do Brasil ANPROTEC, 2000

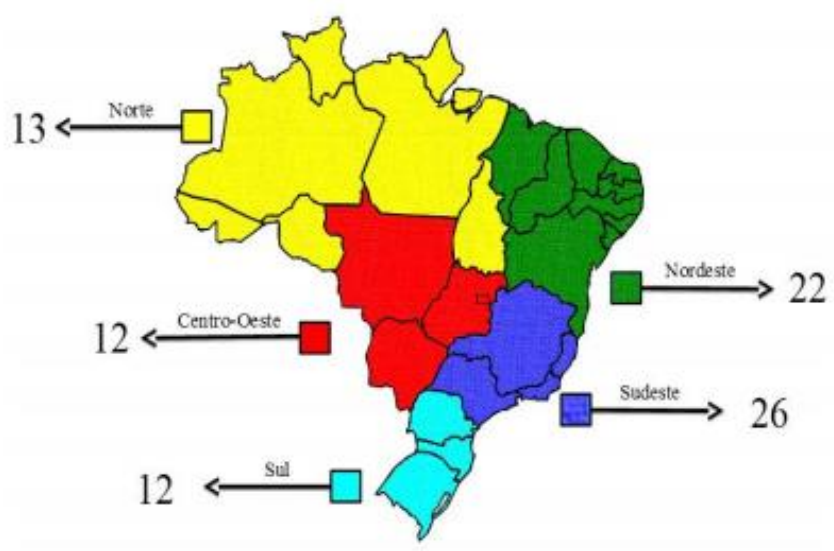

Figura 2 - Mapa Regional das Incubadoras Universitárias

Tabela 1 - Quantidade de Incubadoras Universitárias por região e estado.

\begin{tabular}{|c|c|c|}
\hline Região & Estado & $\begin{array}{c}\text { Quantidade de incubadoras } \\
\text { Universitárias }\end{array}$ \\
\hline \multirow{7}{*}{ Norte } & Acre & 0 \\
\hline & Roraima & 1 \\
\hline & Amazonas & 5 \\
\hline & Rondônia & 1 \\
\hline & Pará & 6 \\
\hline & Amapá & 0 \\
\hline & Tocantins & 1 \\
\hline \multirow{9}{*}{ Nordeste } & Maranhão & 1 \\
\hline & Piauí & 1 \\
\hline & Ceará & 5 \\
\hline & Rio Grande do Norte & 2 \\
\hline & Paraíba & 2 \\
\hline & Pernambuco & 2 \\
\hline & Alagoas & 4 \\
\hline & Sergipe & 1 \\
\hline & Bahia & 4 \\
\hline \multirow{4}{*}{ Centro Oeste } & Mato Grosso & 1 \\
\hline & Mato Grosso do Sul & 2 \\
\hline & Goiás & 5 \\
\hline & Distrito Federal & 4 \\
\hline \multirow{4}{*}{ Sudeste } & Minas Gerais & 7 \\
\hline & Espírito Santo & 1 \\
\hline & São Paulo & 8 \\
\hline & Rio de Janeiro & 10 \\
\hline \multirow{3}{*}{ Santa Catarina } & Rio Grande do Sul & 4 \\
\hline & Paraná & 4 \\
\hline & Santa Catarina & 4 \\
\hline
\end{tabular}




\subsection{O Modelo Hélice Tríplice na visão Governamental}

Quanto ao governo, vários papéis se apresentam no âmbito da tríplice hélice. Além de garantidor da estabilidade,regulador e supervisor,deve ele atuar como capitalista de risco; como incentivador da interação entre universidades públicas e empresas, na busca de soluções a problemas práticos. Pode financiar a pesquisa básica e avançada em áreas identificadas como prioritárias, com base em avaliação de capacidades locais, inclusive de oportunidades de mercado REVISTA EXAME

\subsection{O Modelo Hélice Tríplice na visão das Políticas Públicas}

O Brasil ainda carece de políticas públicas alinhadas a paradigmas da economia do conhecimento, avaliou Rodrigo da Rocha Loures, presidente do Conselho de Inovação e Competitividade da Fiesp, durante o encontro. "É preciso construir ambiente de confiança e de colaboração para romper estratégias da velha economia", disse. REVISTA EXAME

\section{METODOLOGIA}

O artigo assume uma construção exploratória e um levantamento bibliográfico sobre as inovações que chegam as universidades e o distanciamento que existe entre as pesquisas desenvolvidas de maneira ampla no cenário brasileiro, buscando mostrar o desafio na criação de Idéias na Indústria brasileira, a amostragem da Hélice Tríplice e as incubadoras, na visão das universidades no Brasil.

\section{DISCUSSÃO}

Algumas teorias deste artigo destacam de forma geral e específica à importância de analisar o problema do distanciamento entre às pesquisas nas 
universidades e as inovações no mercado brasileiro e sua contribuição para a nossa indústria.

Identificamos o processo de inovação através das universidades brasileiras pela pesquisa, a importância no desenvolvimento econômico, uma amostra do perfil dos nossos cientistas, na figura or, em universidades estrangeiras e o grau de prestígio de nossas universidades ao longo do globo entre 2015 e 2016, o conceito de Hélice Tríplice dentro da estrutura das universidades - governo e da indústria brasileira e na figura 02, um mapa regional das incubadoras brasileiras, juntamente com a tabela or que mostra a quantidade de incubadoras por estados e regiões brasileiras.

\section{CONSIDERAÇÕES FINAIS}

As contribuições deste artigo buscaram de maneira geral e específica, analisar a importância do problema no distanciamento entre as pesquisas das universidades no Brasil e as inovações no mercado brasileiro. Foi mostrada como as incubadoras nas universidades brasileiras estão distribuídas por região, além do conceito de Hélice Tríplice, que busca alinhar participação governamental entre empresas e universidades. A falta de uma política de incentivo levando nossos cientistas a desenvolverem pesquisas em outros países, no detrimento de nossa independência tecnológica nos levando a questionar o papel das universidades na formação de novos mestres e doutores, até mesmo de pesquisadores.

O atraso na inovação levando a refletir na visão das políticas públicas, uma falta de apoio ou mesmo descaso, se torna um desafio na criação de idéias na indústria brasileira, que deveria ter nas universidades as maiores aliadas para continua renovação do seu capital intelectual

No Brasil a relações das universidades com as pesquisas tecnológicas e suas contribuições ainda buscam se encontrar, a fim de, aproximar as empresas das universidades e reduzir às distâncias entre as mesmas. 
Foi mostrada que as inovações Tecnológicas aliadas ao empreendedorismo tem sido fator de grande importância para criação e desenvolvimento, contudo ainda é necessário, no caso do Brasil, uma maior participação e interesse governamental.

\section{REFERÊNCIAS BIBLIOGRÁFICAS}

ANPORTEC. Histórico do setor de incubação de empresas no Brasil e no mundo. 2016.

Disponível em: Acesso em: 20 de maio de 2016.

Ciência e Cultura: O papel da formação de pesquisadores no sistema de inovação, Online version ISSN 2317-666o Cienc. Cult. vol.59 no.4 São Paulo 2007.

CHAIMOVICH, H. Por uma relação mutuamente proveitosa entre universidade de pesquisa e empresas. Revista de Administração, São Paulo, v. 34, n. 4, p. I8-22, out./dez. 1999.

CLOSS, L.; FERREIRA, G. Transferência de Tecnologia Universidade-Empresa: uma revisão das publicações científicas brasileiras no período de 2005-2009. In: ENCONTRO NACIONAL DA ASSOCIAÇÃO NACIONAL DE PÓSGRADUAÇÃO E PESQUISA EM ADMINISTRAÇÃO, 34., 2010. Anais... Rio de Janeiro: ANPAD, 2ого.

Hélice Tríplice: Um Ensaio teórico sobre a relação universidade - UFSC incubadora.periodicos.ufsc.br/index.php/IJKEM/article/viewFile/3309/407I

LEYDESDORFF, L. The triple helix of university-industry-government relations (February 2012). Amsterdam School of Communication Research. University of Amsterdam, Fev., 2012. 
MARZANO, Fábio.Políticas de inovação no Brasil e nos Estados Unidos:a busca da competitividade - oportunidades para ação diplomática. Brasília, DF: Fundação Alexandre de Gusmão,20II.

No mundo da inovação, universidade é agente de desenvolvimento. Revista Veja (2015), Disponível em:

http://no-mundo-da-inovacao-universidade-e-agente-de-desenvolvimento.

Acesso em: 13 de jul de 2015 . 